\title{
The Difference in Negative Scale Score Measured with Positive and Negative Syndrome Scale in Schizophrenic Male Patient Treated with Risperidone in Addition to Vitamin E and Treated with Risperidone Alone at Prof. Dr. M. Ildrem Mental Hospital Medan
}

\author{
Risni Nanda, Elmeida Effendy* (D), Mustafa Mahmud Amin (D) \\ Department of Psychiatry, Faculty of Medicine, Universitas Sumatera Utara, Medan, Indonesia
}

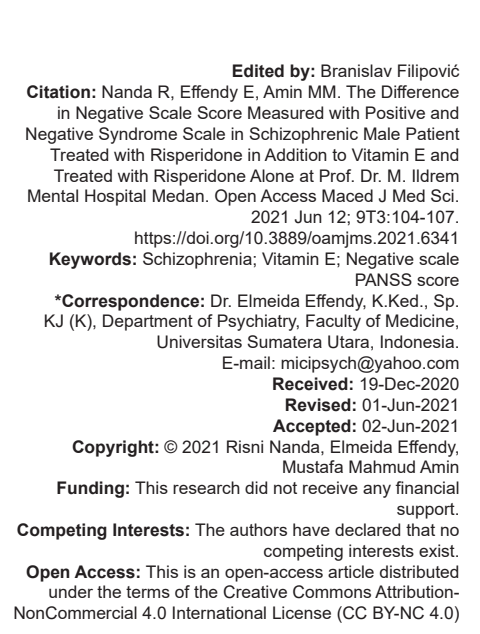

Abstract

OBJECTIVES: The objectives of the study were to investigate the difference in negative scale score in schizophrenic male patients that received vitamin E-fortified risperidone and those receiving risperidone treatments alone.

METHODS: This study was a pre- and post-test experimental design which compared two groups; a group of men with schizophrenia who were given risperidone treatment with added Vitamin $\mathrm{E}$ and another group of men with schizophrenia who were given only risperidone treatment. The study was conducted the outpatient clinic of Prof dr. M. Ildrem Mental Hospital Medan, North Sumatra within August to November 2019. The study has been approved by the Research Ethics Committee of the Faculty of Medicine, North Sumatera University. The instrument used to assess negative scale on the subjects is PANSS

RESULTS: We found that statistical analysis using corrected Mann-Whitney U-test obtained $p<0.001(p<0.05)$

CONCLUSIONS: There was a strongly significant difference in negative scale Positive and Negative Syndrome Scale (PANSS) scores on $4^{\text {th }}$ and $8^{\text {th }}$ weeks in the group which received risperidone treatment with additional Vitamin $\mathrm{E}$ compared to the other group that received risperidone alone.

\section{Introduction}

Schizophrenia is among the top ten diseases in the world, affecting $1 \%$ of population worldwide. Symptoms of schizophrenia generally first appear in early adulthood and will mostly persist despite optimal treatment. In general, early onset of schizophrenia is associated with severe positive and negative symptoms [1]. Schizophrenia in men and women generally has the same prevalence, but the two sexes differ in the onset and course of the disease. The peak age of onset in males is 10-25 years and in females 25-35 years. Schizophrenic outcome was better in women than men [2].

Schizophrenia is a debilitating chronic disease associated with impaired social, cognitive, and emotional functioning. This disease is characterized by positive symptoms (hallucinations and delusions), negative symptoms (blunt emotions and apathy), and cognitive impairment. Positive symptoms often respond to the administration of antipsychotic drugs, whereas negative and cognitive symptoms do not [3]. According to the classic dopamine hypothesis, schizophrenia is associated with increased dopaminergic activity in certain brain structures. The increase in dopaminergic activity is greatly related to an increase in the number and sensitivity of dopaminergic D2 receptors and overproduction or reduced destruction of dopamine. Classic antipsychotics such as haloperidol, fluphenazine serve as dopamine D2 receptor antagonists while second generation antipsychotics such as risperidone, olanzapine, and others are known to have high affinity for other receptors as well, such as the serotonin receptor (5HTA2) which exerts therapeutic effects on negative symptoms and cognitive deficits that were once difficult to treat [4].

A number of studies have continuously investigated the etiology of schizophrenia, one of which is the role of oxidative stress in the pathogenesis of schizophrenia. Oxidative stress occurs due to an imbalance in the oxidative mechanism as a result of increased levels of oxidants and decreased levels of antioxidants [5]. Free radicals, which are normally 
generated as a waste from metabolic processes, are highly reactive, leading membrane dysfunction. Membrane dysfunction will cause free radicalmediated abnormalities resulting in a number of clinical consequences including prominent negative symptoms. There is a complex antioxidant defense system that protects against oxidative stress, leading to decreased antioxidant defense system (AODS) in schizophrenia [6].

Reactive oxygen species are free radicals that are formed in the body; at least $5 \%$ of the inhaled oxygen produces reactive oxygen species. This excessive free radicals will cause oxidative stress. Oxygen in the aerobic process will undergo reduction and form water, but the partially reduced oxygen will be active and naturally are able to interact with DNA molecules, carbohydrates, lipids, and proteins. Excessive production of reactive oxygen species which exceeds the antioxidant defense system will lead to the damage of macromolecules including DNA, lipids, and proteins. Due to the high use of oxygen in the brain, the brain becomes more vulnerable to oxidative stress. Vitamin $\mathrm{E}$, in the other hand, is known for its favorable effect in protecting cell membrane caused by free radicals and lipid [7]

From the above description, it was found that oxidative stress is one of the etiopathogenesis of schizophrenia which contributes to the development of a number of significant clinical consequences including prominent negative symptoms. In the other hand, Vitamin $E$ is known for its protective effect against oxidative stress. Hence, we would like to investigate whether or not the addition of Vitamin $E$ to risperidon treatment leads to differences in negative scale scores compared to treatment with risperidone alone.

\section{Methods}

\section{Patient sample}

This study was a pre- and post-test experimental design, which compared two groups; a group of men with schizophrenia who received risperidone treatment with added Vitamin $\mathrm{E}$ and $\mathrm{a}$ group of men with schizophrenia who received only risperidone treatment. This study was conducted at outpatient clinic of Prof. dr. M. IIdrem Mental Hospital Medan, North Sumatra from August to November 2019. Patients that were enrolled in this study had to meet our inclusion criteria; (1) male with schizophrenia who had been diagnosed based on Pedoman Penggolongan dan Diagnosis Gangguan Jiwa di Indonesia III (PPDGJIII); (2) aged between 20 and 45 years; (3) in the stabilization phase of treatment; (4) received $6 \mathrm{mg}$ risperidone treatment; (5) negative scale Positive and Negative Syndrome Scale (PANSS) score for each item $\geq 4$; (6) body mass index of $18.50-24.99 \mathrm{~kg} / \mathrm{m}^{2}$; and (7) are willing to participate in the study. The exclusion criteria were as follows; (1) having a general medical disorder; (2) history of substance use (except caffeine and nicotine); and (3) history of using supplements containing Vitamin $E$ in the past 2 weeks. This study has already been approved by the Research Ethics Committee of Faculty of Medicine, North Sumatera University. Through this study, we ensured that our participants were already given appropriate explanation and that all participants gave consent willingly. Samples were taken consecutively until 37 subjects were given risperidone with Vitamin $E$ supplementation and 37 subjects were given risperidone alone. The grouping of subjects into the intervention or control group was carried out by random allocation using a coin toss system so that each subject had the same opportunity to enter the intervention or control group. Patients in intervention group were given risperidone treatment with additional Vitamin E $2 \times 400 \mathrm{IU}$ [8], [9]. After the $4^{\text {th }}$ and $8^{\text {th }}$ weeks, negative scale scores in both groups were remeasured. This research is an on-treatment analysis, that is, if there are subjects who drop out, they will be replaced by new subjects. Subjects that fall into the drop out category are those who did not complete treatment or subjects who experienced side effects. If side effects, such as extrapyramidal disturbances occur, the subject will be given additional trihexyphenidil ranging from 5 to $15 \mathrm{mg} /$ oral/day.

\section{Statistical analysis}

The analysis of the data was carried out using a statistical package for service solution software program (SPSS ver. 22). Before statistical analysis, normality test was carried out using the Shapiro-Wilk test. The Friedman + Post hoc Wilcoxon test was used to see the difference in the negative scale PANSS score in men with schizophrenia at week 0 , the end of week 4, and the end of week 8. Furthermore, to see the difference in negative scale PANSS scores in the subjects at the end of the $4^{\text {th }}$ week $8^{\text {th }}$ week, repeated Mann-Whitney U-tests was performed with corrections.

\section{Results}

The characteristics of the subjects are presented in Table 1. For categorical variables, the unpaired categorical comparative test was performed with the Chi-square test. For numerical variables, an unpaired numerical comparative test was performed. Before these statistical tests, the normality test was carried out using Shapiro-Wilk test. As our data was 
Table 1: Demographic characteristics

\begin{tabular}{|c|c|c|c|}
\hline Variable & $\begin{array}{l}\text { The group that received } \\
\text { risperidone and vitamin } E \\
n=37\end{array}$ & $\begin{array}{l}\text { The risperidone } \\
\text { only group } \\
n=37\end{array}$ & $\mathrm{p}$ \\
\hline \multicolumn{4}{|l|}{ Age (year) } \\
\hline Mean \pm SD & $33.70 \pm 3.83$ & $33.32 \pm 3.60$ & $0.66^{*}$ \\
\hline \multicolumn{4}{|c|}{ Educational level, n (\%) } \\
\hline Primary school & $16(43.20)$ & $13(35.10)$ & \multirow[t]{3}{*}{$0.75^{\star *}$} \\
\hline Middle school & $16(43.20)$ & $19(51.40)$ & \\
\hline University & $5(13.50)$ & $5(13.50)$ & \\
\hline \multicolumn{4}{|c|}{ Marital status, n (\%) } \\
\hline Married & $9(24.30)$ & $11(29.70)$ & \multirow[t]{2}{*}{$0.79^{* *}$} \\
\hline Unmarried & $28(75.70)$ & $26(70.30)$ & \\
\hline \multicolumn{4}{|c|}{ Occupational status, n (\%) } \\
\hline Employed & $10(27.00)$ & $12(32.40)$ & \multirow[t]{2}{*}{$0.80^{* \star}$} \\
\hline Unemployed & $27(73.00)$ & $25(67.60)$ & \\
\hline \multicolumn{4}{|l|}{ Initial week BMI } \\
\hline Mean \pm SD & $19.47 \pm 0.34$ & $19.49 \pm 0.34$ & $0.91^{*}$ \\
\hline \multicolumn{4}{|c|}{ Initial week negative scale PANSS score } \\
\hline Mean \pm SD & $31.43 \pm 1.62$ & $31.41 \pm 1.69$ & $0.94^{*}$ \\
\hline
\end{tabular}

normally distributed, statistical analysis was continued using unpaired $t$ test.

From the Shapiro-Wilk test, we found that our data were still not distributed normally with a $p<0.05$ in spite of data transformation. Thus, we continued the test by using the Friedman + Post hoc Wilcoxon test. Table 2 shows the difference in negative scale PANSS scores in men with schizophrenia who were given treatment with supplemental Vitamin E, at week 0 , week 4 , and week 8 , analyzed with Friedman + Post hoc Wilcoxon test. We found that in intervention group that was given risperidone treatment with additional Vitamin $\mathrm{E}$ at week 0 , the median value of the negative scale PANSS score was 31.00 (minimum 29.00-maximum 34.00). At week 4, the median value was 29.00 (26.00-31.00), and at week 8 the median value was 25.00 (23.00-28.00). There was a strongly significant difference in the negative scale PANSS score at week 0 , week 4 , and week 8 , with a value of $p<0.001$.

Table 2: Differences in negative scale PANSS scores in men with schizophrenia who were given risperidone treatment with supplemental Vitamin E, at Week 0, Week 4, and Week 8

\begin{tabular}{lll}
\hline PANSS score negative scale & Median (minimum-maximum) & $\mathrm{p}$ \\
\hline Week 0 & $31.00(2900-34.00)$ & $<0.001^{*}$ \\
Week 4 & $29.00(26.00-31.00)$ & \\
Week 8 & $25.00(23.00-28.00)$ & \\
\hline Friedman + Post hoc Wilcoxon test. & &
\end{tabular}

From the Shapiro-Wilk test, we obtained that the data were not normally distributed with a $p$ $<0.05$, even though the data had been transformed. Table 3 shows the difference in negative scale PANSS scores in men with schizophrenia who were given Risperidone treatment alone, at week 0 , week 4 , and week 8 , analyzed with Friedman + Post hoc Wilcoxon test. We then continued the analysis using Friedman + Postt hoc Wilcoxon test, and found the result at week 0 , the median value of the negative scale PANSS score was 31.00 (minimum 29.00-maximum 34.00), at week 4 the median value was $30.00(28.00-32.00)$, and at week 8 the median value was $28.00(26.00-31.00)$, in men with schizophrenia who were given risperidone treatment alone. There was a very significant difference in the negative scale PANSS score at week 0 , week 4 , and week 8 , with a value of $p<0.001$.
Table 3: Differences in negative scale PANSS scores in men with Schizophrenia who were given risperidone treatment alone, at Week 0, Week 4, and Week 8

\begin{tabular}{lll}
\hline PANSS score negative scale & Median (minimum-maximum) & $\mathrm{p}$ \\
\hline Week 0 & $31.00(29.00-34.00)$ & $<0.001^{*}$ \\
Week 4 & $30.00(28.00-32.00)$ & \\
Week 8 & $28.00(26.00-31.00)$ & \\
\hline${ }^{*}$ Friedman + Post hoc Wilcoxon test. & &
\end{tabular}

From Table 4, we found that the data were not normally distributed (Shapiro-Wilk test). Thus, we continued the analysis using repeated MannWhitney U-test with corrections, the results obtained in the group that was given risperidone treatment with added Vitamin $\mathrm{E}$ at week 4 the median value of the negative scale PANSS score was 29.00 (minimum 26.00-maximum 31.00), at week 8 the median value was 25.00 (23.00-28.00). Whereas in the group given risperidone treatment alone at week 4 the median value of the negative scale PANSS score was 30.00 (28.00-32.00), at week 8 the median value was 28.00 (26.00-31.00). There was a very significant difference in the negative scale PANSS score at week 4 and week 8 between the group that was given risperidone treatment with Vitamin $E$ supplementation and the group that was given risperidone treatment alone with a value of $p<0.001$.

Table 4: Differences in negative scale PANSS scores in men with Schizophrenia who were given risperidone treatment with supplemental Vitamin $\mathrm{E}$ and who were given risperidone alone, at week 4 and week 8

\begin{tabular}{llll}
\hline PANSS score & Risperidone + Vitamin E & Risperidone & $\mathrm{p}$ \\
negative scale & Median (minimum-maximum) & Median (minimum-maximum) & \\
\hline $4^{\text {th }}$ week & $29.00(26.00-31.00)$ & $30.00(28.00-32.00)$ & $<0.001^{*}$ \\
$8^{\text {th }}$ week & $25.00(23.00-28.00)$ & $28.00(26.00-31.00)$ & \\
\hline${ }^{*}$ The Mann-Whitney U-test is repeated with corrections. & &
\end{tabular}

\section{Discussion}

In this study, intervention group showed the median value of the negative PANSS score at week 4 the median value was 29.00 (minimum 26.00maximum 31.00), and at week 8 the median value was 25.00 (23.00-28.00). Whereas in the group given risperidone treatment alone at week 4 the median value of the negative scale PANSS score was 30.00 $(28.00-32.00)$, at week 8 the median value was 28.00 (26.00-31.00).

There was a very significant difference in negative scale PANSS scores on week 4 and week 8 between the group that was given risperidone treatment with added Vitamin $\mathrm{E}$ and the group that was given risperidone treatment alone with a value of $p<0.001$. The results of this study are consistent with a study conducted by Ghodake et al. in India in 2012 which studied 40 subjects who were given haloperidol treatment with additional Vitamin C $250 \mathrm{mg}$ and Vitamin E 400 IU once a day, with a value of $p=0.024$ [10]. A 
study by Gunes et al. in Turkey in 2017 on 71 subjects by measuring the levels of Total Antioxidant Level (TAL), Total Oxidant Level (TOL), and Oxidative Stress Index (OSI) in the group of patients with schizophrenia and healthy controls with $p<0.05$. The results showed that there was a statistically significant positive correlation between Total Oxidant Level (TOL) and a negative PANSS score in the patient group with schizophrenia with a value of $r=0.36$ with a value of $p=0.002 .^{5}$

Macromolecular damage caused by oxidative stress plays a role in schizophrenia, as well as the failure of antioxidant defenses to protect against damage to cell membranes caused by free radicals. Free radicals that play a role in schizophrenia are hydrogen peroxide, hydroxyl radical, nitric oxide, and superoxide radical. Hydroxyl radicals are produced by hydrogen peroxide and nitric oxide, which promote apoptosis, DNA damage, and lipid peroxidation. Meanwhile, Vitamin E is an antioxidant that can inhibit lipid peroxidation [11].

In our study, we only enrolled male participants to avoid bias considering that in female the occurrence of negative symptoms and changes in brain morphology were already known to be less frequent. Moreover, schizophrenic female patients show better response of neuroleptics treatment. These particular advantages in women are thought to be related to estrogen which naturally serves as antioxidant. The intrinsic structure of antioxidants lies in the phenolyc part of steroid compounds, which enhances the activity of antioxidant enzymes, thus poses a neuroprotective effect against oxidative stress. Mitochondria bind to estrogens thereby increasing mitochondrial efficiency, which, in turn, reduces intracellular oxidative stress [12].

We also acknowledge that our study poses several limitations as it only assessed the negative PANSS score at week 0 , the end of week 4 , and the end of week 8 [9] but did not investigate the exact onset when the changes began. This study is an open clinical trial which was not conducted on multicenter bases. The strength of this research is that it is the first research conducted in North Sumatra, especially in Prof. dr. M. Ildrem Mental Hospital Medan.

\section{Conclusion}

From the results of this study, it was concluded that Vitamin E had an effect on decreasing the negative scale Positive and Negative Syndrome Scale (PANSS) score in schizophrenic patients.

\section{References}

1. Arroll MA, Wilder L, Neil J. Nutritional interventions for the adjunctive treatment of schizophrenia: A brief review. Nutr J. 2014;13:91. https://doi.org/10.1186/1475-2891-13-91 PMid:25228271

2. Sadock BJ, Sadock VA. Schizophrenia Spectrum and Other Psychotic Disorders. In: Kaplan and Sadock's Synopsis of Psychiatry Behavioral Sciences, Clinical Psychiatry. $11^{\text {th }}$ ed. Philadelphia, PA: Lippincott Willias \& Wilkins; 2015. p. 301. https://doi.org/10.1097/00004850-198907000-00008

3. Brown HE, Roffman JL. Vitamin supplementation in the treatment of schizophenia. CNS Drugs. 2014;28(7):611-22. https://doi.org/10.1007/s40263-014-0172-4

\section{PMid:24846474}

4. Buskovic M, Vovk T. Can supplementation with Vitamin E or $\mathrm{C}$ and omega-3 or 6 fatty acids improve the outcome schizophrenia? Rev Sci Artiles. 2008;59:167-73.

5. Gunes M, Altindag A, Bulut M, Demir S, Ibiloglu AO, Kaya MC et al. Oxidative metabolism may be associated with negative symptoms in schizophrenia. Psychiatry Clin Psychopharmacol. 2017;27:54-61. https://doi.org/10.1080/24750573.2017.1293243

6. Yao JK, Keshavan MS. Antioxidant, Redox Signaling, and Pathophysiology in Schizophrenia: An integrative View. New York: Mary Ann Liebert Inc.; 2011. p. 2011-35.

7. Pandya CD, Howell KR, Pillai A. Antioxidants as potential therapeutics for neuropsychiatric disorder. Prog Neuropsychopharmacol Biol Psychiatry. 2013;46:214-23. PMid:23123357

8. Combs GF, McClung JP. Vitamin E. In: The Vitamins Fundamental Aspects in Nutrition and Health. $5^{\text {th }}$ ed. Amsterdam: Elsevier Inc.; 2017. p. 207-42.

9. Aggarwal BB, Sundaram C, Prasad S, Kannappan R. Tocotrienols, the Vitamin $\mathrm{E}$ of the $21^{\text {st }}$ Century: Its potential against cancer and other chronic diseases. Biochem Pharmacol. 2011;80(11):1613-31. https://doi.org/10.1016/j.bcp.2010.07.043 PMid:20696139

10. Ghodake SR, Suryakar AN, Padalkar RK, Shaikh K. The effect of combined Vitamine $\mathrm{E}$ and $\mathrm{C}$ supplementation on the oxidative stress parameters in patients with schizophrenia. Biochem Indian J. 2012;6:155-61.

11. Lin $\mathrm{CH}$, Lane HY. Early identification and intervention of schizophrenia: Insight from hypotheses of glutamate dysfunction and oxidative stress. Fourt Psychiatry. 2019;10:93. https://doi. org/10.3389/fpsyt.2019.00093

PMid:30873052

12. Doi N, Hoshi Y, Itokawa M, Yoshikawa T, Ichikawa T, Arai M, et al. Paradox of schizophrenia genetics: Is a paradigm shift occuring? Behav Brain Funct. 2012;8:1-18. https://doi. org/10.1186/1744-9081-8-28 